\title{
Ecoturismo e design: caminhos para sustentabilidade em Chapada Gaúcha (MG)
}

\author{
Ecotourism and design: paths to sustainability in \\ Chapada Gaúcha (MG, Brazil)
}

\author{
Nadja Maria Mourão, Rita de Castro Engler, Lidja Mourão Lataro Hoehne
}

\begin{abstract}
RESUMO
As interfaces do Ecoturismo com o Design buscam direcionar os caminhos para o desenvolvimento sustentável. Este artigo relata uma experiência com três comunidades de artesãos no município de Chapada Gaúcha. O município é território intermediário entre o Parque Nacional Grande Sertão Veredas e o Parque Estadual de Serra das Araras, região noroeste do Estado de Minas Gerais/Brasil. Esta região foi popularizada pelo escritor João Guimarães Rosa e pertence a uma das sub-bacias do Rio Francisco. Artesãos das comunidades de Serra das Araras, Ribeirão do Areia e Buraquinhos forneceram os elementos da pesquisa. Foi investigada a possibilidade de inclusão do ecoturismo e do design para o desenvolvimento de produtos artesanais com resíduos vegetais do bioma Cerrado. As atividades desenvolvidas tiveram como pré-requisito dados de levantamento sócio, econômico, cultural e ambiental, de projetos antecessores e acompanhamento das comunidades, anteriormente. A proposta é parte da pesquisa "Design sistêmico: sustentabilidade na produção artesanal com resíduos vegetais do Cerrado Mineiro", como atividade-ação prevista no projeto. O desenvolvimento do ecoturismo é uma das metas do município. A natureza é um dos principais atrativos na região e tem a infraestrutura como principal problema. Entre as atividades desenvolvidas, buscou-se sensibilizar a comunidade quanto à utilização dos resíduos vegetais, principalmente do uso dos buritis, pois esta é uma palmeira em abundância nas comunidades. A metodologia de trabalho foi definida respeitando os múltiplos olhares e vozes dos moradores, buscando resgatar e valorizar as identidades e os conhecimentos locais. O resultado deste trabalho possibilitou uma nova visão em relação aos produtos artesanais, à medida que os artesãos perceberam a identidade do território. Verificou-se que as riquezas oriundas da biodiversidade e da cultura podem ser a base para o desenvolvimento de produtos e atrativos para o ecoturismo. É necessário buscar caminhos entre o ecoturismo e o design, que auxiliem a economia local, apresentando valores sociais, culturais e ambientais.
\end{abstract}

PALAVRAS-CHAVE: Ecoturismo; Design; Sustentabilidade. 


\section{ABSTRACT}

The interfaces of Ecotourism with Design are seeking paths to sustainable development. This article reports an experiment with three artisan communities in the municipality of Chapada Gaúcha (MG, Brazil). The municipality is the middle ground between the National Park "Grande Sertão Veredas" and State Park of "Serra das Araras", northwest of Minas Gerais. This region was popularized by the writer João Guimarães Rosa and belongs to a sub-basin of Rio Francisco. Artisans form communities of Serra das Araras, Ribeirao do Areias and Buraquinhos provided the data for this research. The possibility of inclusion of ecotourism and design to develop handicraft products with residues of the Cerrado region were investigated. The activities were developed based on a survey of socio, economic, cultural and environmental projects and monitoring of communities predecessors in the previous year. The proposal is part of the research "Systemic Design: Sustainability in craft production with vegetable residue from Cerrado Mineiro" as a field activity planned in the project. The development of ecotourism is one of the goals of the municipality. Nature is one of the main attractions in the region and infrastructure is the main problem. Among the activities, we tried to raise awareness of the community on the use of crop residues, especially the use of buritis because this palm is in abundant in the region. The methodology was defined respecting multiple perspectives and voices of residents, seeking to rescue and value their identities and local knowledge. The result of this work provided a new vision in relation to artisanal products, as the craftsmen realized how important it is to value identity of the region. It was found that the wealth derived from biodiversity and culture can be the basis for the development of products and attractions for ecotourism. It is necessary to find paths between ecotourism and design, which help the local economy, with social values, cultural and environmental.

KEYWORDS: Ecotourism; Design; Sustainability.

\section{Introdução}

$\mathrm{Na}$ atualidade, com os efeitos de descaracterização culturais do mundo pós-globalizado, os turistas buscam por roteiros turísticos que se adéquam aos seus anseios e preferências, suas condições pessoais e possibilidades, privilegiando o bem-estar de todos e o encontro com a natureza.

Conforme o Ministério do Turismo, o governo reconhece essas tendências de consumo como oportunidades de valorizar a diversidade e as particularidades do Brasil. Por isso, propõe a segmentação como uma estratégia para estruturação e roteiros turísticos. O Ecoturismo se estabelece nos princípios e critérios da sustentabilidade socioambiental, associado ao processo de planejamento participativo, com integração intersetorial e inserção da comunidade local, contemplando as necessidades de infraestrutura e qualificação profissional e a gestão sustentável (MTur, 2010).

O design, cada vez mais, se destaca em produtos e serviços de todas as áreas e setores. Ele utiliza as ferramentas do mercado para 
desenvolvimento de produtos como um todo, e se estabelece consciente de sua responsabilidade social e ecológica em resultados inovadores.

As interfaces do Ecoturismo com o Design buscam direcionar os caminhos para o desenvolvimento sustentável. O design sustentável, conjunto de ferramentas, conceitos e estratégias que visam desenvolver soluções em sistemas, serviços ou produtos, busca satisfazer às necessidades do presente, sem comprometer o desenvolvimento das gerações futuras.

Artesãos das comunidades de Serra das Araras, Ribeirão do Areia e Buraquinhos do município de Chapada Gaúcha - Minas Gerais/ Brasil forneceram os elementos para o desenvolvimento desta pesquisa. Este município é território intermediário entre o Parque Nacional Grande Sertão Veredas e o Parque Estadual de Serra das Araras, noroeste de Minas Gerais. Pertence ao Vale do Urucuia, região popularizada pelo escritor João Guimarães Rosa, pertencente a uma das sub-bacias do Rio Francisco.

O desenvolvimento do turismo é uma das metas do município, que busca implementar atividades ecologicamente corretas. A natureza é um dos principais atrativos na região e tem a infraestrutura como principal problema.

Foi investigada a possibilidade de inclusão do design, para 0 desenvolvimento produtos artesanais com resíduos vegetais do Cerrado da região, visando promover o turismo local.

Este artigo relata parte da investigação em pesquisa-ação com as três comunidades citadas, no município de Chapada Gaúcha. A metodologia de trabalho foi definida respeitando a diversidade e as tradições locais, buscando resgatar e valorizar as identidades e a cultura.

\section{Procedimentos e métodos}

Os procedimentos consistem na delimitação das questões, realizar as observações e interpretar resultados, com base nas relações encontradas, fundamentando-se nas teorias científicas existentes.

A metodologia deste trabalho consiste na revisão, contextualização e análise do referencial teórico, que possibilita análise científica dos dados, em todo o processo de investigação. Assim, permanece a busca pela eficácia dos dados registrados e outros que possam contribuir com os objetivos, nas temáticas de: sustentabilidade, ecoturismo e design sustentável. O objeto da pesquisa são as comunidades de Buraquinhos, Ribeirão do Areia e Serra das Araras, em Chapada Gaúcha.

A etapa seguinte do trabalho consta da realização de oficinas de Design, identidade e cultura, para os participantes da pesquisa, artesãos e produtores artesanais das comunidades selecionadas. É estabelecido o estudo de caso a partir de observação participante, conforme Yin (2005).

São selecionados alguns produtos artesanais, de acordo com a metodologia adotada. Analisam-se as práticas desenvolvidas pela comunidade, através dos dados e resultados obtidos. O método do design sustentável, a partir dos resíduos gerados no ciclo de produção e serviços, 
aponta quais os procedimentos melhor aproveitam os recursos, estimula a reutilização de materiais e beneficia o meio ambiente.

As atividades desenvolvidas tiveram como pré-requisito dados de levantamento sócio, econômico, cultural e ambiental, de projetos antecessores e acompanhamento das comunidades no ano anterior. A proposta é parte da pesquisa "Design sistêmico: sustentabilidade na produção artesanal com resíduos vegetais do Cerrado Mineiro", parte das atividades da pesquisa-ação prevista no projeto.

Entre as atividades desenvolvidas, cita-se a sensibilização da comunidade quanto à utilização dos resíduos vegetais, principalmente do uso da palmeira de buriti, espécie em abundância na região.

\section{Definições: sustentabilidade, ecoturismo e design}

A interseção dos termos sustentabilidade, design e ecoturismo são traçados pela possibilidade de atuação da pesquisa, em comunidades potencializadas pelo turismo e produtos sustentáveis.

Tratando-se da sustentabilidade, as discussões desenvolvidas em diversos encontros mundiais durante as últimas décadas acerca do tema, foram de grande importância para o conhecimento da fundamentação ambiental, social e econômica. Transversalmente, a sustentabilidade percorre os setores socioculturais, políticos, econômicos e territórios, nos debates sobre desenvolvimento sustentável. Segundo o IUCN ${ }^{1}$ (1987 apud VEIGA, 1993, p.153):

O conceito de desenvolvimento sustentável envolve limites não limites absolutos, mas restrições impostas pelo atual estado da tecnologia e da organização social aos recursos naturais e pela capacidade de absorção dos efeitos das atividades humanas pela biosfera.

Para que a sustentabilidade se consolide é necessário que essa seja inserida se possível em todas as atividades por meio da mudança de postura e principalmente da atitude humana, em relação à sociedade e ao meio ambiente. Envolve diversos desafios, por ser um tema que carece de um longo período de transição que afeta o comportamento atual da sociedade.

A sustentabilidade vincula-se "à temática cultural, à sociedade e ao próprio ser humano. Está associada ao compromisso social e relacionada ao processo participativo de construção" (LOURES, 2009, p. 59). Desta forma, se consolida na qualidade de vida através do relacionamento entre as necessidades humanas, os ambientes e grupos sociais.

Conforme Brito (2011), o desenvolvimento sustentável propõe mudanças sociais, políticas, econômicas e ambientais no intuito de não comprometer os sistemas ecológicos e sociais das comunidades. Trata-se de um tema que envolve diversos setores e na atividade turística estudamse os conceitos, na tentativa de colaborar com um desenvolvimento mais responsável nos municípios com essa vocação. 
O ecoturismo é um segmento diferenciado da 'indústria do turismo', porque implica necessariamente planejamento que leva a sustentabilidade do ambiente natural e cultural, e que deve também conduzir ao desenvolvimento regional sustentável, a um maior conhecimento do mundo natural e cultural visitado e a uma maior conscientização do turista no que se refere a comportamentos (CEBALLOS-LASCURÁIN apud KINKER, 2002).

Para atender ao turismo em bases sustentáveis, o design se insere nesta proposta potencializando o território, os materiais e a possibilidade de estabelecer novos paradigmas de vida sustentável.

Design é atualmente um termo popular, utilizado em todos os meios de comunicação, expressando atributos de qualidade e funcionalidade. Bonfim (1998) considerou que estes predicativos incidem sob a expansão do design para outros aspectos, buscando qualificá-lo como processo criativo, inovador e provedor de soluções. Apresentou o design como instrumento qualificado para alcançar a inovação através de vantagens competitivas, buscando outras áreas de produtos e serviços.

O design se inova através de planejamento, estratégia, marketing, qualidade e forma de produção. Estes procedimentos, citados acima, reorganizam as relações com os resultados alcançados. Contudo, o objetivo principal desta profissão é servir ao ser humano, seja nas relações entre os serviços, produtos ou ambos simultaneamente.

O desafio de promover a sustentabilidade no design é evidenciado por Manzini (2008), que considera dois critérios importantes que devem ser adotados: buscar uma abordagem estratégica do design e em segundo lugar, levar seriamente em consideração os critérios da sustentabilidade.

\section{Descrição do Local: O Vale do Urucuia}

A Bacia Hidrográfica do Rio Urucuia nasce na Serra Geral de Goiás, fronteira desse Estado com Minas Gerais. Suas águas atravessam morros e chapadões, no sentido oeste-leste até chegar ao rio São Francisco. Geologicamente, a maioria dos tipos de solo dessa bacia é parte da Formação Urucuia, que apresenta idade variável entre 80 e 50 milhões de anos (MENDES, 2011).

Os municípios pertencentes à Bacia do Urucuia em Goiás são Buritis e Cabeceiras e em Minas Gerais: Formoso, Arinos, Chapada Gaúcha, Pintópolis, Uruana de Minas, Urucuia, Riachinho, Bonfinópolis de Minas e São Romão, Conforme Mendes (2011), a bacia hidrográfica em questão também é integrante do "Aquífero Urucuia". Trata-se de um grande reservatório de águas subterrâneas, pouco conhecido, ocupando uma extensão de $500 \mathrm{~km}$, que necessita de estudos hidrogeológicos específico. Sua área de abrangência tem início no Alto Urucuia onde estão os rios formadores desta bacia como o Piratinga e o São Domingos.

Sua história é descrita por Mendes (2011, p.139): 
A história do URUCUIA - este grande vale afluente da margem esquerda do rio São Francisco - está diretamente vinculada à colonização do Centro-oeste do Brasil e do Norte de Minas. Com a descoberta de ouro em Minas Gerais em 1694, cresceu progressivamente a penetração de garimpeiros, tropeiros, pecuaristas e aventureiros de toda espécie para o Sertão, sobretudo após a descoberta também do ouro em Goiás e Mato Grosso nas décadas de 1720/1730. Esse fluxo de pessoas e mercadorias transformou o Vale do Urucuia em trevo de contatos entre as regiões mineradoras do Centro-oeste e os Currais do São Francisco, zona de criação de gado que ia do norte de Minas à região Nordeste. Essas relações comerciais, políticas, culturais e até familiares se intensificaram com a oficialização, em 1736, por D. João V, da Estrada Real Picada da Bahia.

Conforme o autor, o Vale do Urucuia se transformou principalmente pelo fluxo de pessoas e mercadorias, culminando na popularização da região, intensificada pelas relações e pela busca do ouro. Mendes (2011) descreve que, nesta época, o Urucuia era "povoado" por sertanejos vaqueiros, cavaleiros e tropeiros, tocadores de grandes boiadas porque a pecuária era a principal atividade econômica da região. Após a inauguração de Brasília, Distrito Federal, em 1960 a pecuária foi substituída pelo agronegócio, pois os municípios da região são parte da fronteira agrícola que se alarga a partir do Centro-oeste destruindo o Cerrado, cenário de "Grande Sertão: Veredas", de João Guimarães Rosa.

$\mathrm{Na}$ Figura 1, retratam-se os buritis caídos e sombra sob a água fresca, no leito arenoso e limpo do Rio Feio (que de feio não tem nada), em Serra das Araras, Município de Chapada Gaúcha (MG), cenário semelhante às descrições de Guimarães Rosa (2001, p.26): " $E$ verde e barrento, quente e espeta (...) o senhor consome essa água, ou desfaz o barranco, sobra cachoeira alguma? Viver é negócio muito perigoso..."

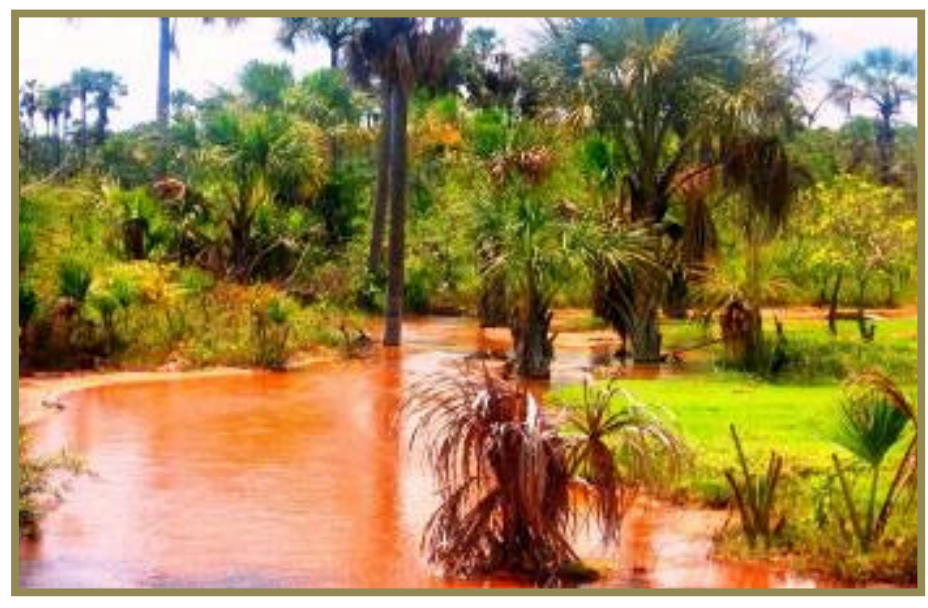

Figura1: Buritis do "Rio Feio", Distrito de Serra das Araras, Município de Chapada Gaúcha (MG). Fonte: Mourão (2011).

Figure 1: Buritis the " Rio Feio", District of Serra das Araras, municipality of Chapada Gaucha (MG, Brazil). Source: Mourão (2011). 
O Urucuia de Guimarães Rosa, o Urucuia dos tropeiros e dos garimpeiros, o Urucuia dos bandeirantes e pecuaristas, é hoje o Urucuia em busca do desenvolvimento sustentável. Esta região está desenvolvendo o Ecoturismo, sob os olhares atentos do IEF - Instituto Estadual de Florestas e do ICMbio - Instituto Chico Mendes.

\section{O Município de Chapada Gaúcha}

Chapada Gaúcha é um dos municípios do Vale do Urucuia, geograficamente no alto do Estado de Minas Gerais, próximo à divisa com os estados de Goiás e Bahia. A região do Vale do Urucuia, entre os séculos XIX e XX, foi um cenário de conflitos envolvendo grandes fazendeiros da região. Os fazendeiros - conhecidos como coronéis, comandavam grupos de jagunços, que se agregavam aos vaqueiros, para guardar as fazendas e participar das disputas territoriais. Os jagunços (apelido dado aos homens que trabalhavam para os coronéis) tornaram-se bandos que guerreavam no sertão em nome de seu patrão. Alguns eram aliados a favor do governo, outros eram contra, transformando-os em personagens históricos característicos da região. Até os dias atuais, os personagens dos jagunços permanecem como mito, mantidos pela cultura popular. Assim, as comunidades preservam as características expressas no vestuário, no jeito de falar e de se relacionar, na alimentação, nas rodas de música e de conversa, ou seja, na vida cotidiana do sertanejo, dados do IBAMA/Funatura (2003).

Conforme Kelsen (2007), Antônio Dó foi um cangaceiro muito popular, segundo os moradores mais velhos da região. Lutou contra as arbitrariedades que o governo fazia com a população local. Além da existência de publicações sobre Antônio Dó, os moradores contam estórias sobre sua trajetória no território. A visitação ao túmulo deste cangaceiro, está aos poucos se tornando popular no turismo na Região. Muitas pessoas desejam conhecer melhor, e de perto, as histórias dos cangaceiros e se envolvem com os moradores locais para ter acesso ao túmulo do mesmo.

A antiga Vila dos Gaúchos, hoje município de Chapada Gaúcha, teve seu início de povoamento no ano de 1976, quando chegaram os primeiros moradores procedentes do Rio Grande do Sul, pelo projeto PADSA - Projeto de Assentamento Dirigido a Serra das Araras, que agregava os municípios de Formoso, Arinos, Januária, São Francisco e o povoado de Vila dos Gaúchos, conforme biblioteca digital do IBGE.

Ocorreu um fato inédito no Estado de Minas Gerais, pois Chapada Gaúcha foi o único povoado que virou Distrito e Município no mesmo ano, em 1995, com a junção do Distrito de Serra das Araras, criando assim o mais novo município do Grande Sertão Veredas. O município de Chapada Gaúcha é jovem ainda, mas suas tradições descendem de tempos remotos dos tropeiros e dos garimpeiros, Mendes (2011). Estas particularidades tornam o local atrativo aos turistas que visitam os parques da região, pois desejam conhecer de perto as mudanças que estão ocorrendo no município. Alguns turistas solicitam aos fazendeiros para visitar suas terras, somente por curiosidade - é provável que esta modalidade do turismo, se desenvolva na região. 
Visualiza-se na Figura 2, a localização do município de Chapada Gaúcha e a localização das comunidades e Buraquinhos, Ribeirão do Areia e Serra das Araras, objetos da pesquisa. Estas comunidades apresentam intensa tradição cultural, localizadas na região centro-oeste do município. $O$ Distrito de Serra das Araras possui acesso pela estrada principal, porém as comunidades de Buraquinhos e Ribeirão do Areia, o acesso é precário e oposto uma da outra.

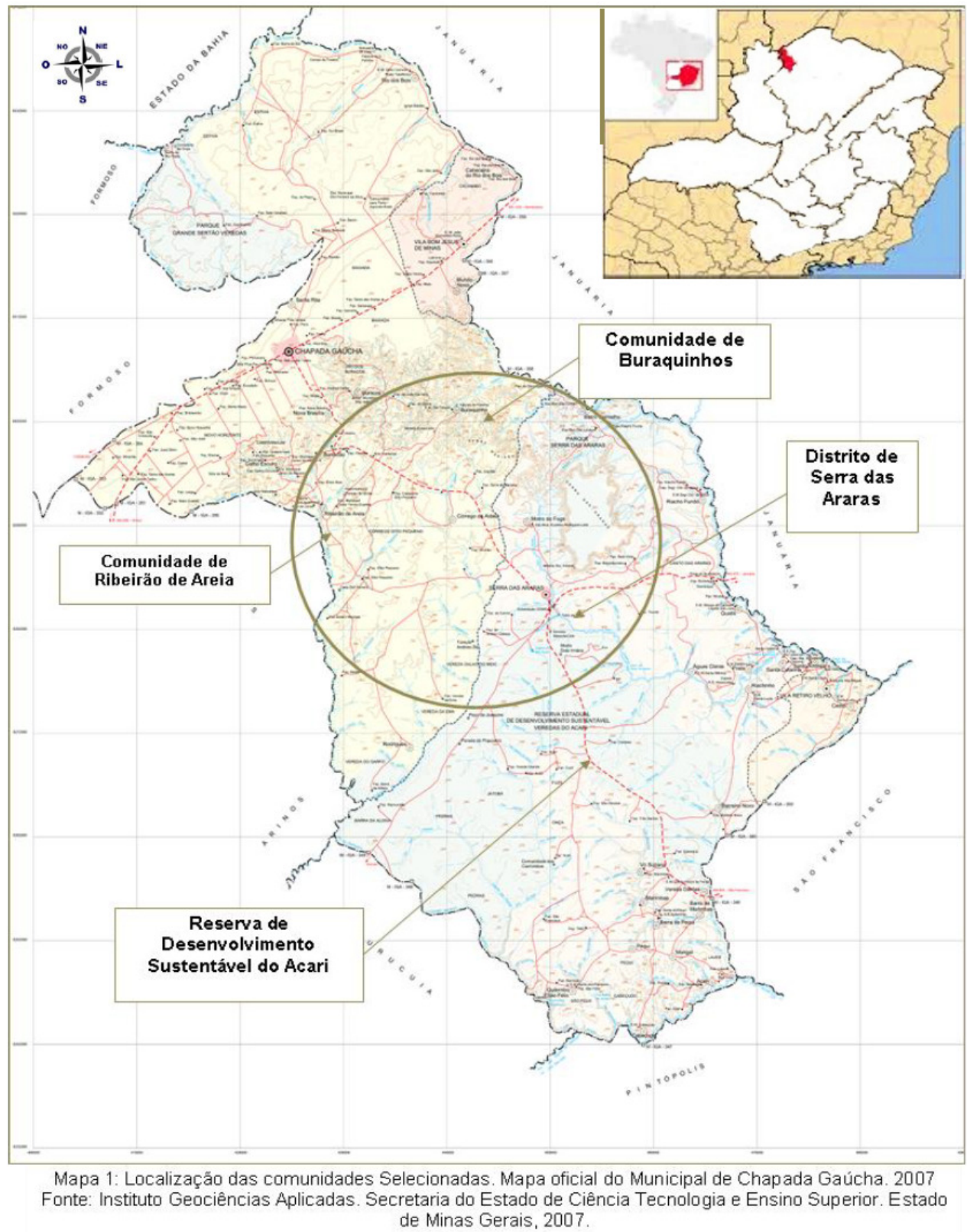

Figura 2: Localização das comunidades selecionadas. Mapa oficial do Município de Chapada Gaúcha e sua localização em Minas Gerais/Brasil. Fonte: Instituto Geociências Aplicadas. Secretaria de Ciência Tecnologia e Ensino Superior. Governo do Estado de Minas, (2007).

Figure 2: Location of selected communities. Official map of the municipality of Chapada Gaucha and its location in Minas Gerais / Brazil. Source: Instituto Geociências Aplicadas. Secretaria de Ciência Tecnologia e Ensino Superior. Governo do Estado de Minas, (2007). 
Economicamente, o município de Chapada Gaúcha, com população de 10.266 habitantes ${ }^{2}$, é o que mais cresce no Estado de Minas Gerais, caminhando para um desenvolvimento agrosilvopastoril acelerado por o maior produtor de sementes de capim do país, deixando a condição exploradora e extrativista, para se tornar um município potencialmente econômico e tecnológico.

No entorno do município estão localizadas duas Unidades de Conservação Estaduais - Parque Estadual Serra das Araras e Reserva Estadual de Desenvolvimento Sustentável Veredas do Acari. Situado na divisa dos estados de Minas Gerais e Bahia, o Parque Grande Sertão Veredas - Unidade de Conservação Nacional é uma das atrações turísticas da região.

O Parque Estadual da Serra das Araras se destaca pelos paredões na paisagem. Seus diversos ecossistemas, considerados como de preservação permanente, e seus sítios geomorfológicos que funcionam como habitat e criadouro natural de espécies de arara-vermelha e arara Canindé, que dão nome a serra, conforme descrição do IEF.

O Parque Nacional Grande Sertão Veredas tem em seu nome uma homenagem explícita ao escritor João Guimarães Rosa. Sua passagem na região, no início da década de 50, resultou em uma das mais importantes obras literárias brasileiras, o romance Grande Sertão: Veredas, repleto de passagens que descrevem os locais, a relação do homem com a natureza e as características culturais, ainda hoje encontradas (IBAMA, 2003).

As comunidades do município de Chapada Gaúcha são formadas pela diversidade de povos que interagem no mesmo território.

\section{As comunidades e suas tradições}

A questão das populações tradicionais merece uma introdução, pois o novo conceito de populações tradicionais é resultante da preocupação que a humanidade passou a ter com o meio ambiente, nos últimos trinta anos. Conforme Silva (2010), a análise da destruição e da conservação dos recursos naturais, permitiu perceber a existência de populações capazes de utilizar e ao mesmo tempo conservar tais recursos, estes grupos humanos passaram a ser chamados de populações tradicionais.

A inserção dos povos tradicionais, no contexto ambiental, passou a existir a partir da discussão sobre a presença de seres humanos nas Unidades de Conservação. Os países pioneiros na criação de Unidades de Conservação estabeleceram uma tradição de que dentro das mesmas não poderia haver a presença dos humanos. No entanto, Silva (2010), expõe que a situação encontrada em países em desenvolvimento, como o Brasil, que apenas há poucos anos criaram suas áreas de preservação e conservação, obrigou a examinar com maior profundidade a relação entre o homem e o meio ambiente. Foi observado que realmente existem populações cuja ação é altamente benéfica para a conservação do meio ambiente. Também existem aqueles que exploram todos os recursos, tornando-se nômades dentro do território de locação. 
Na cidade de Chapada Gaúcha, o abastecimento de água é precário, uma contradição com as veredas ao entorno. Cerca de $60 \%$ não possuem água encanada e em metade do município não há rede de coleta e tratamento do esgoto, ficando a cargo das fossas a destinação do mesmo, conforme Salgado (2010, apud MOSAICO, 2009).

De maneira ainda precária, a população do campo reside em habitações sem acabamento, desenvolvidas a base dos recursos naturais disponíveis no cerrado, apresentando construções que utilizam barros como o adobe e pau-a-pique, e com cobertura de palhas e folhas de buriti, frequentes no meio rural, segundo IBAMA/Funatura (2003).

Contudo é um povo festeiro, alegre e sempre pronto para coisas novas. Esta mistura de gaúchos e sertanejos concedeu um aspecto diferenciado aos hábitos da cidade.

A cultura gaúcha está em cada detalhe: nas casas de carnes, churrasco, muita erva-mate, cuia e chimarrão em toda parte. É comum ter chimarrão nas casas e nos ambientes de trabalho, sem contar as torcidas do Grêmio e do Colorado, que tem o mesmo ou até mais espaço que as mineiras. Conforme informações da Prefeitura de Chapada Gaúcha, até pouco tempo os gaúchos somavam $80 \%$ da população, hoje o número já está proporcionalmente menor, em torno de 50 ou $60 \%$. Mesmo assim, os hábitos dos gaúchos foram incorporados e socializados.

Além do chimarrão e do churrasco, os gaúchos trouxeram do sul para os sertões as festas e as danças. Na obra literária "Grandes Sertões Veredas" são narradas os desacertos íntimos do personagem quando declara: "o sertão é dentro da gente". Estranhamente, a convivência entre os povos é cheia de contradições, um mosaico de diversidades culturais. Observa-se na Figura 3, um gaúcho e um sertanejo caminhando ao trote dos cavalos. Cenas que somente nesta região podem ser assistidas naturalmente. Esta relação desperta o interesse do turismo, que incentiva aos habitantes a manterem suas identidades de origem.

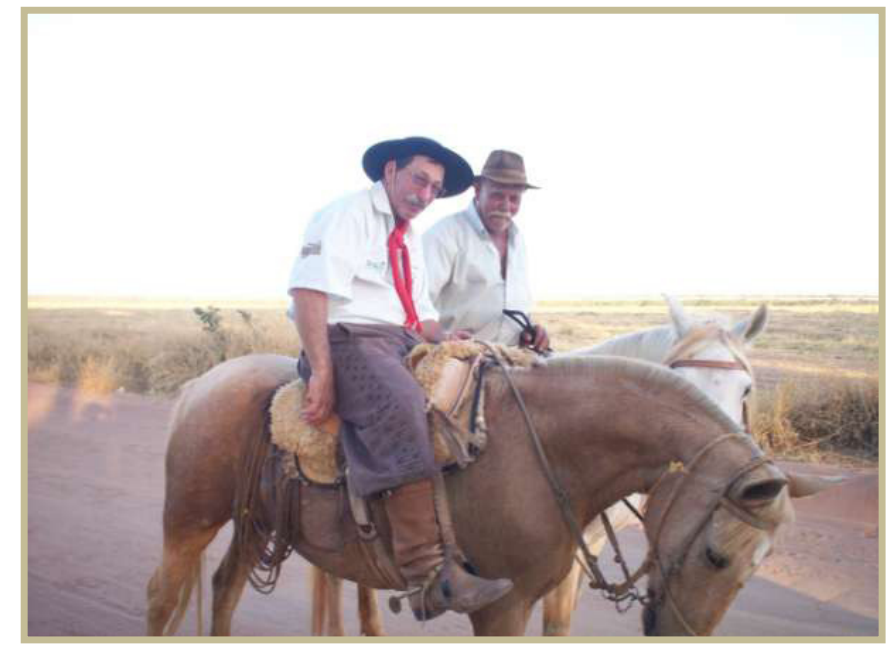

Figura 3: Gaúcho e sertanejo, personagens locais. Fonte: SEMAT/ sem data, conforme Salgado (2010).

Figure 3: Gaucho and sertanejo, local characters. Source: SEMAT / undated, as Salgado (2010). 
Com o objetivo de destacar a riqueza cultural da região, há mais de dez anos, é realizado o evento "Encontro dos Povos do Grande Sertão Veredas", no mês de julho (Figura 4). A proposta do evento é consolidar as manifestações culturais das populações tradicionais que habitam o entorno do Parque Nacional Grande Sertão Veredas e Associação dos Municípios do Circuito Turístico Urucuia Grande Sertão e Velho Chico. Este encontro, conforme Prefeitura de Chapada Gaúcha, estimula a troca de experiências, à comercialização de produtos sustentáveis do cerrado e a discussão sobre políticas públicas, que promovem o desenvolvimento sustentável e social do município.

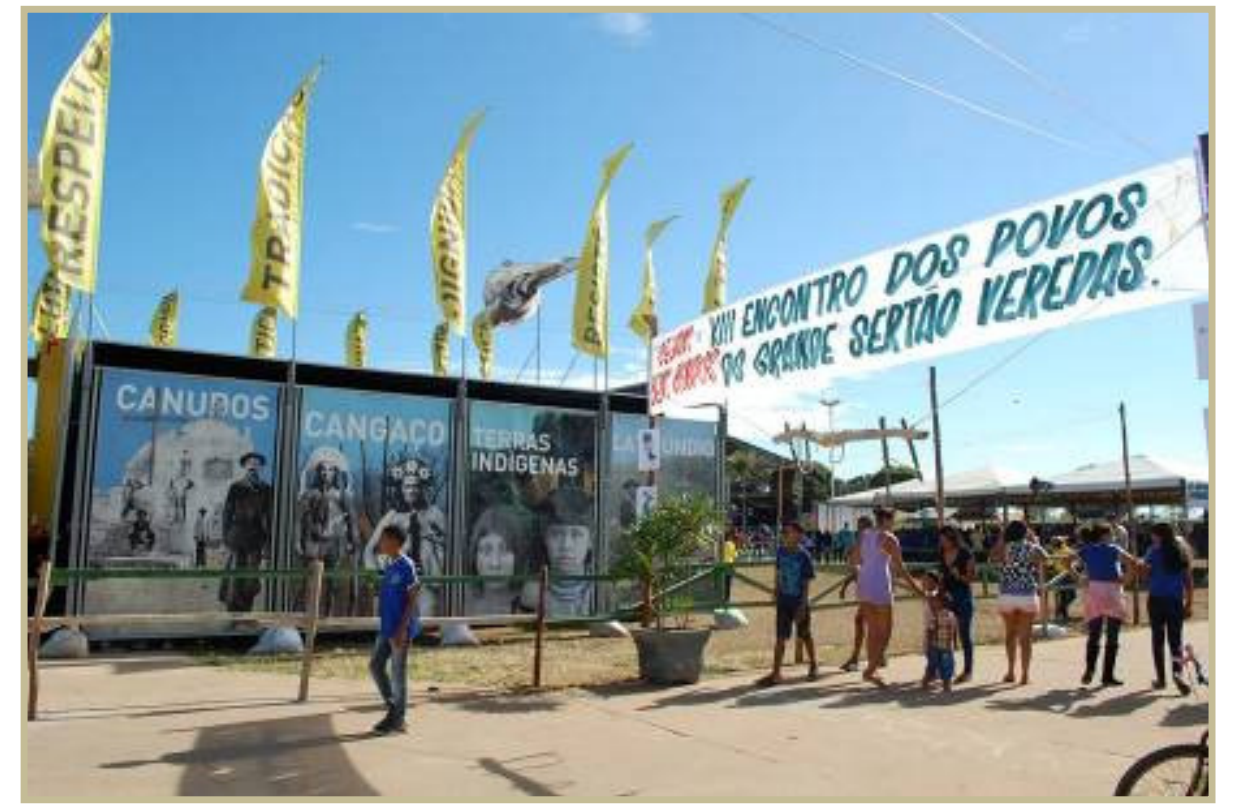

Figura 4: XIII Encontro dos Povos do Grande Sertão Veredas. Fonte: Mourão (2014). Figure 4: XIII Meeting of Peoples of the Grande Sertão Veredas. Source: Mourão (2014).

O Centro de Tradição Gaúcha de Chapada Gaúcha busca manter a tradição entre os mesmos, entre festas e comemorações de origem dos pampas. Deve-se citar também o festejo das "Folias de Reis" dos sertanejos, sempre no início do mês de janeiro, que reuni várias comunidades do município. Estes eventos atraem numerosos turistas, em procura de cultura, artesanato, conhecimento, integração e religiosidade (IBGE, 2007).

\section{A comunidade de Serra das Araras}

O distrito de Serra das Araras possui uma rica cultura fundamentada nas tradições sertanejas, citado quatro vezes no livro "Grande Sertão: Veredas". Estas citações atraíram turistas à região, que recebeu esta denominação pela grande predominância de araras vermelhas da fauna local. Hoje, protegidas pelo Parque Estadual de Serra das Araras.

É um povoado com todas as características de uma cidade do interior: a praça, o comércio local, a igreja e a simplicidade do povo que vive e conserva as tradições no distrito, dados do IBAMA/Funatura (2003). 
Retrata-se na imagem da Figura 5, a mansidão das ruas do distrito de Serra das Araras, que suportam o sol e o calor característico da região.

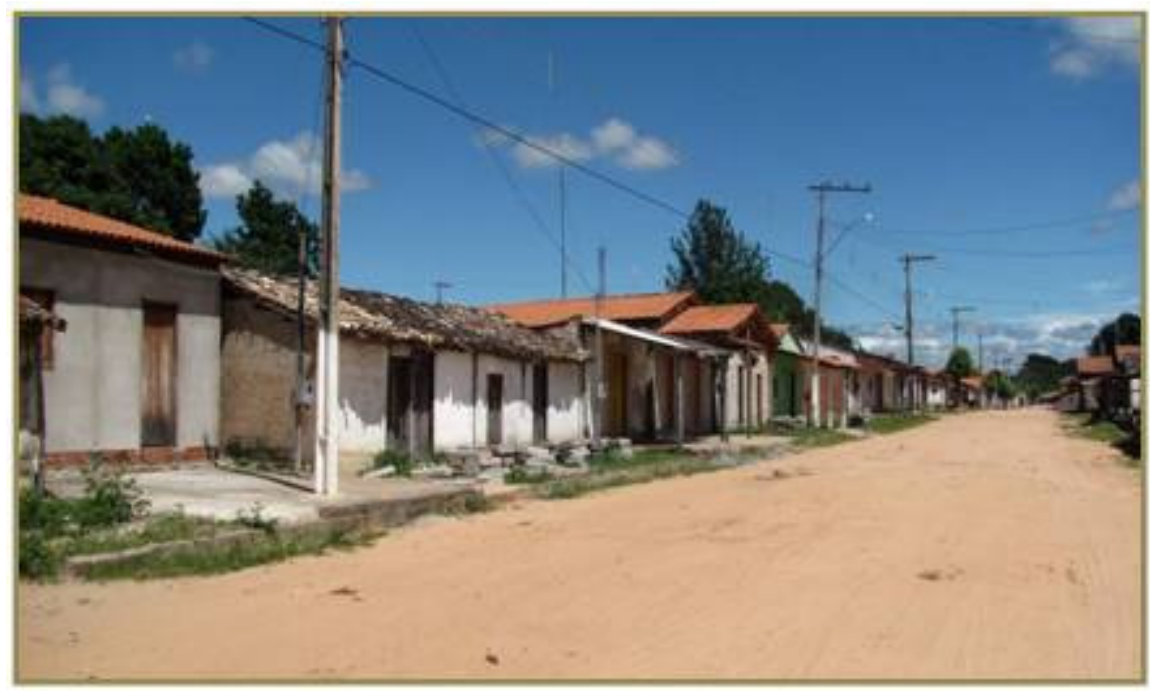

Figura 5: Ruas do Distrito de Serra das Araras. Fonte: Mourão (2011).

Figure 5: Streets of the District of Serra das Araras. Source: Mourão (2011).

Em Serra das Araras, predominam as veredas e também comunidades com culturas especiais. Um exemplo disso é a comunidade quilombola São Félix, que há pouco tempo recebeu o título de remanescente de escravos. Até meados de 2010, nem luz elétrica existia, fato que poderá mudar os hábitos da região, com a influência dos meios de comunicação.

O grupo de dança São Gonçalo de Serra das Araras é hoje o representante da cultura local. O grupo viaja com frequência pelos municípios vizinhos de Chapada Gaúcha, levando a tradição do povo de Serra. O grupo São Gonçalo é constituído por homens e mulheres e também por alguns jovens, conforme Kelsen (2007).

\section{A comunidade de Ribeirão do Areia}

A comunidade de Ribeirão de Areia fica na divisa dos municípios de Chapada Gaúcha e Arinos. O principal rio é o de Ribeirão de Areia e alguns afluentes: Barrocão, Cafarnaum e Invernada. A vegetação é composta de veredas, veredinhas, platôs, buritis, pequizeiros, enfim, abundância de beleza que compõe o cerrado. Para chegar ao lugarejo, é necessário atravessar vários bancos de areia e o riacho que dá o nome a região. Brotam mudas de buritis, em meio à estrada arenosa. É comum encontrar carros de bois e vaqueiros acompanhando o gado de uma pastagem a outra.

Os primeiros moradores da comunidade de Ribeirão de Areia, em sua maioria eram posseiros da fazenda chamada "Meninos". A descendência dos moradores da comunidade é originária de varias regiões: Januária, São Francisco, Formoso, Carinhanha, Buracos e outros lugares mais.

O lugarejo, desde 1954 vem se construindo e escrevendo sua história. Possui uma diversidade cultural onde os moradores procuram manter suas 
tradições, através de danças, brincadeiras, festas e outros. Também se concentra uma variação linguística, na qual estas pessoas herdaram de seus antepassados que foram os primeiros moradores daquela região. Uma das maiores características está no conhecimento de diversos tipos de plantas medicinais, pé de pequi, cabeça de nego, o buriti, a cagaita e outros.

A região possui potencial de agricultura familiar, onde os moradores colhem e tem a oportunidade de vender seus produtos na feira do pequeno produtor rural na sede do município de Chapada Gaúcha.

No Ribeirão de Areia, todos os anos comemora-se a Folia de Reis e nesta época, os moradores como também pessoas de outros lugares, vão até lá, festejar a folia. Há também representantes de instituições governamentais e ONGS - Organizações não governamentais, que participam para registrarem a cultura do povoado. A Folia de Reis é uma das mais tradicionais festas típicas na região, na qual os foliões se deslocam de fazenda em fazenda por um período de 10 dias - entre final de dezembro e início de janeiro. Enquanto o evento acontece, os moradores e visitantes se confraternizam, proporcionado e reencontro entre parentes e amigos, os quais se encontram para a diversão naturalmente intrínseca à festa.

Os tocadores e festeiros da comunidade de Ribeirão do Areia se reúnem para preparação de festas e apresentações em eventos culturais, com os jovens da comunidade (Figura 5). Senhor Jonas Pereira Gomes (Figura 6), representante da cultura local, fundou o "Grupo de Cultura Popular" na comunidade, que mantêm as tradições sertanejas.

Senhor Jonas não é apenas o líder da cultura local. Em função da difusão cultural, acompanhou outros grupos até o Distrito Federal, por diversas vezes, em busca de apoio à região. É um produtor rural que, semelhante a outros sertanejos, criou sua família nos moldes da tradição de tocador de viola e incentivador das manifestações culturais e religiosas do sertão mineiro. Durante o período de festas, todos os filhos e netos são convocados a participarem dos eventos, tocando e dançando.
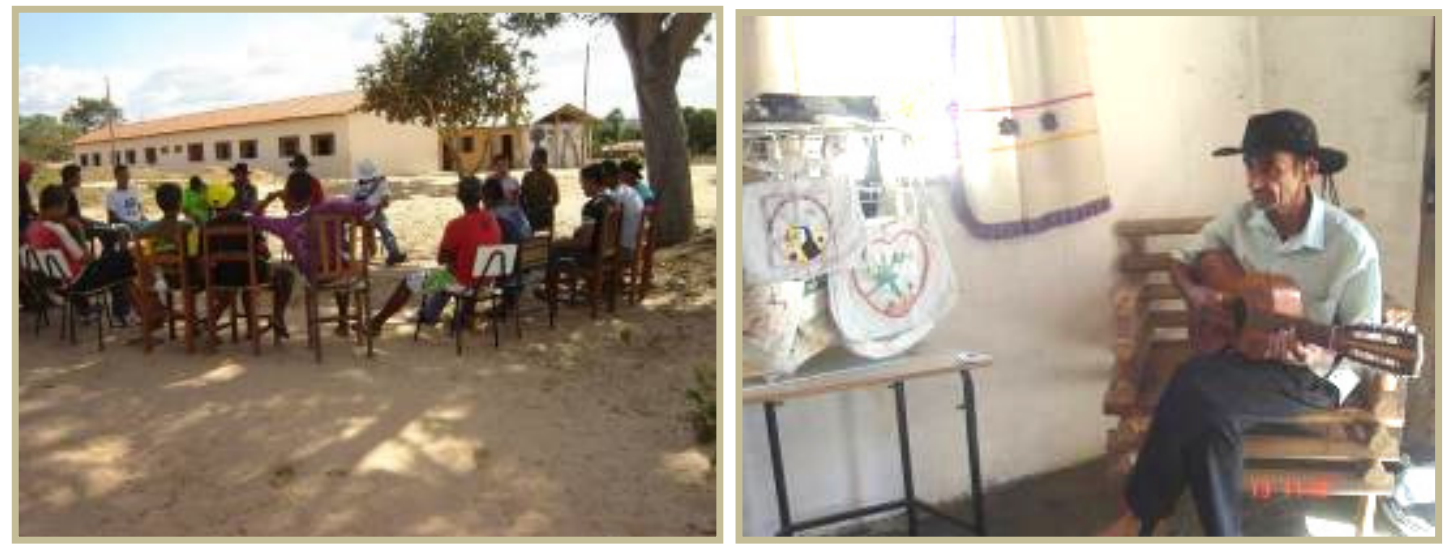

Figuras 6 e 7: Preparação para Eventos Culturais na comunidade de Ribeirão do Areia. À direita, Sr. Jonas Pereira Gomes, representante da Cultura local. "Grupo de Cultura Popular”. Fonte: Projeto Grio do Instituto Rosa Sertão/CG - s/data.

Figures 6 and 7: Preparing for Cultural Events in Ribeirão da Areia community. Right, Mr. Jonas Gomes Pereira, representative of the local culture. "Group of Popular Culture." Source: Projeto Grio do Instituto Rosa Sertão/CG - no date. 


\section{A comunidade de Buraquinhos}

Localizada na zona rural do município de Chapada Gaúcha, a comunidade de Buraquinhos é reconhecida e citada regionalmente por sua beleza paisagística e pela riqueza cultural de seus moradores. Constituída por uma população familiar de origem quilombola, Buraquinho situa-se no Corredor Ecológico Vão dos Buracos, área de ligação entre o PNGSV e o PESA, apresentando fatores extremamente relevantes para a riqueza socioambiental da região (IBAMA/FUNATURA, 2003).

O lugarejo de Buraquinhos (Figura 7), distintamente de Serra das Araras, apresenta uma comunidade geograficamente dispersa, ficando as casas dispostas ao longo do rio Pardo e guardada a devida distância de segurança contra cheias. São, na sua grande maioria, casas de adobe e cobertura de palha de buriti. Ademais das casas, a comunidade carece de estrutura em muitos outros aspectos (ZATZ, 2004).

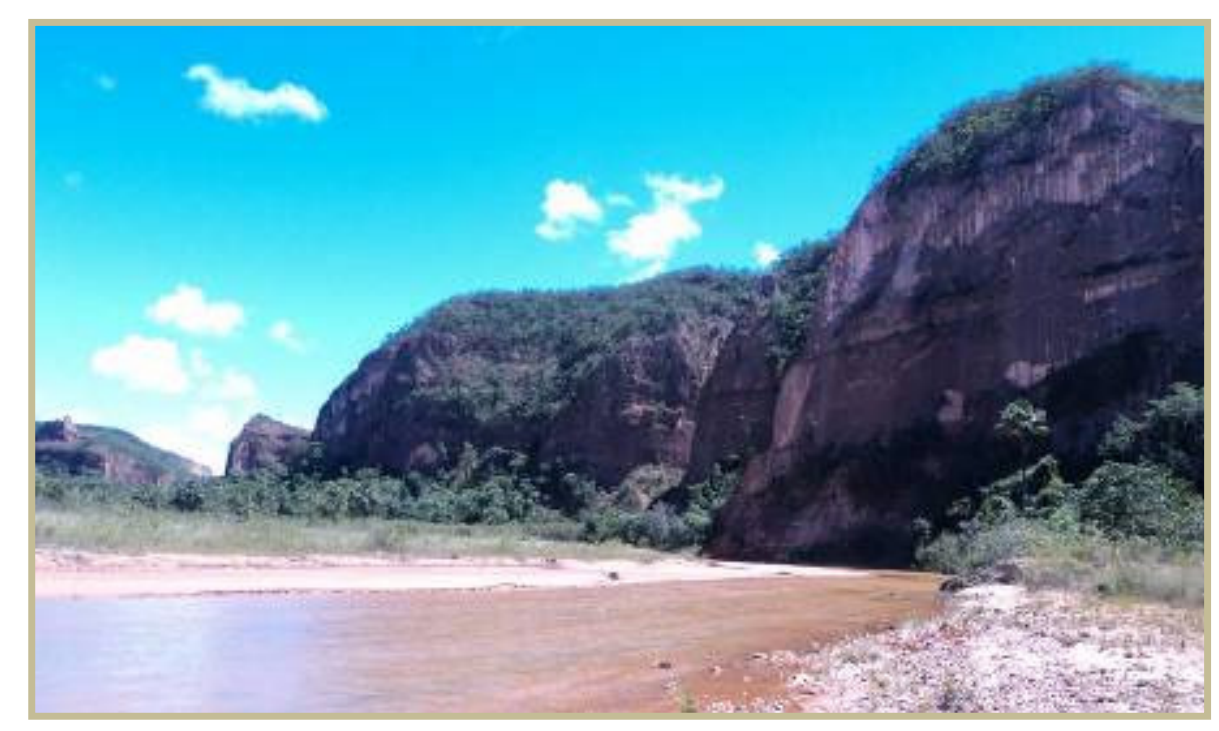

Figura 8: Chapadão da Comunidade de Buraquinhos. Fonte: Mourão (2011). Figure 8: Chapadão Community of holes. Source: Mourão (2011).

A comunidade não possui água encanada, tratamento de água ou sequer instalações sanitárias, mas a energia elétrica está presente desde 2010, através do programa "Luz para Todos". Para limpeza, higiene pessoal ou para lavagem de louça e de roupa a água é transportada diretamente nas águas do Rio Pardo, bem perto da comunidade.

Vivem do plantio de mandioca, milho, feijão e hortaliças, entre outras. Executam atividades artesanais quase que por falta de opção. Pois a região é bastante acidentada geograficamente e cheia de buritis. Assim, para produzirem esteiras e outros objetos com o tear de buriti, basta ir ao "quintal" de casa.

O turismo na região de Buraquinhos é precário. O motivo principal é a dificuldade de acesso e a falta de infraestrutura, até mesmo para os moradores locais. Porém, os mais ousados, enfrentam todas as intempéries, para admirarem a beleza e pureza da região, cravada entre os paredões. 


\section{$\mathrm{O}$ artesanato e o design em comunidades tradicionais}

O artesanato das comunidades se preservara através das técnicas tradicionais, de gerações em gerações. No entanto, em busca da preservação e das soluções ambientais, o artesanato se inova na rede do design sustentável.

Atualmente, 0 design se expande para outros limites - a sustentabilidade, em busca de um método criativo, inovador e provedor de soluções. Os recursos transversais do design excedem os domínios produtivos, tecnológicos e econômicos. Deste modo, envolvem aspectos que visam o ser humano ético, social, cultural e ambiental, em um sistema de rede aprimorando a função do design.

As propriedades culturais e as questões locais são fatores importantes. Moraes (2008) esclarece que para entender o paradigma brasileiro, com toda sua energia e pluralidade, é necessário refletir sobre as probabilidades para o design no mundo global. Os conflitos podem gerar tensão e confronto intrícito de uma sociedade heterogênea, híbrida e plural, como também de grande diversidade cultural. É oportuno ressaltar, que a falta de unicidade no design brasileiro não provém da falta de cultura, mas, ao contrário, do seu excesso (MORAES, 2008).

Assim, onde há remanescentes da cultura quilombolas, de tribos indignas, de passagem de sertanejos, ou de tantos outros que se firmaram no sertão das veredas, há também uma identidade multicultural.

\section{As oficinas de design, cultura e identidade}

Utiliza-se o termo "oficinas" para aplicação de atividades que promovam o conhecimento, em curto tempo ${ }^{3}$. Neste caso, desenvolveu-se uma proposta sintética com conteúdos básicos de design, cultura e identidade, com foco em sustentabilidade, para o público das comunidades da pesquisa.

A proposta didática foi elaborada, visando promover o protagonismo da comunidade, com base na experiência dos métodos praticados pela pesquisadora - designer e professora arte educadora. A programação das oficinas foi executada em duas etapas:

Primeira etapa: são desenvolvidas atividades para sensibilização e observação do contexto socioambiental, através de elementos para percepção das cores, texturas, formas, ambiente e da cultura. Nesta etapa, são fornecidos os conceitos de design, sustentabilidade e ecoturismo, na perspectiva de que a comunidade possa desenvolver produtos artesanais que atendam às vocações de desenvolvimento local.

Segunda etapa: aplicam-se atividades práticas, utilizando resíduos vegetais coletados pelos participantes. Nesta prática, são observadas as técnicas, a percepção espacial e criatividades na utilização dos materiais empregados pelos artesãos.

As oficinas possibilitam ao pesquisador observar o grupo no desenvolvimento das atividades artesanais (materiais e técnicas), na 
apropriação dos conteúdos e da identidade. Têm como objetivo a integração dos participantes, incentivando-os para troca de informações com a equipe do projeto. São registrados os resultados da percepção ambiental, que possibilitam aos artesãos conhecerem melhor o meio ambiente no qual estão inseridos.

Para cada comunidade foi identificado, através das visitas técnicas, alguns costumes relacionados com as tradições e atividades culturais. Realizadas no período e janeiro a julho/2013, procurou-se analisar quais os conhecimentos de produção artesanal e da sociedade local, do turismo, cultura e do meio ambiente, se apresentam na produção artesanal. Buscouse identificar características locais, em busca de soluções em economia criativa, que atendam ao turismo na região, preservando os recursos naturais.

Visando o desenvolvimento do ecoturismo, a produção artesanal é conduzida pelo design potencializando o território, o respeito aos recursos naturais, quanto materiais para produção e a possibilidade dos artesãos serem multiplicadores dos valores ambientais fornecidos durante as oficinas.

Os conteúdos se apoiam na cresça que, no domínio humano, a sustentabilidade é perfeitamente compatível com o respeito à integridade cultural, à diversidade cultural e ao direito básico das comunidades à autodeterminação e à auto-organização (MEDEIROS, 2006 et al., apud CAPRA, 2002).

A associação das Bordadeiras e Artesões de Serra das Araras elabora produtos para comercialização durante a Festa de Santo Antonio. O evento promove encontro de várias comunidades e realizam feiras para venda de produtos, inclusive imagens de Santo Antônio, esculpidas dos talos da palmeira de buriti.

A Oficina de design realizada na "Associação das Bordadeiras e artesões de Serra das Araras" estimulou o desenvolvimento de oratórios utilizando o mesmo material, para compor e adequar às imagens de Santo Antônio. As imagens podem ser comercializadas com melhor estética e segurança para o transporte. Este produto atende as metas, abordando os valores da identidade local, através dos materiais e técnicas utilizadas. As flores e os detalhes inseridos são representações do meio ambiente e confeccionadas com resíduos vegetais.

Nas imagens da Figura 9 estão retratadas a sequencia de produção e novas embalagens, incluindo o oratório de São Antonio, executadas pela artesã Maria Rosicley de Araujo Almeida.

Em Ribeirão do Areia, o destaque é a Folia de Reis. Todos os anos, muitas pessoas se deslocam para acompanhar o evento na comunidade, que segue a tradição de várias gerações. Assim, a Oficina de Design, para comunidade e membros da "Associação dos Artesãos de Ribeirão do Areia", buscou as características dos foliões e as cores da Folia de Reis. Os produtos artesanais devem receber detalhes que identifiquem a comunidade local e sua cultura. 


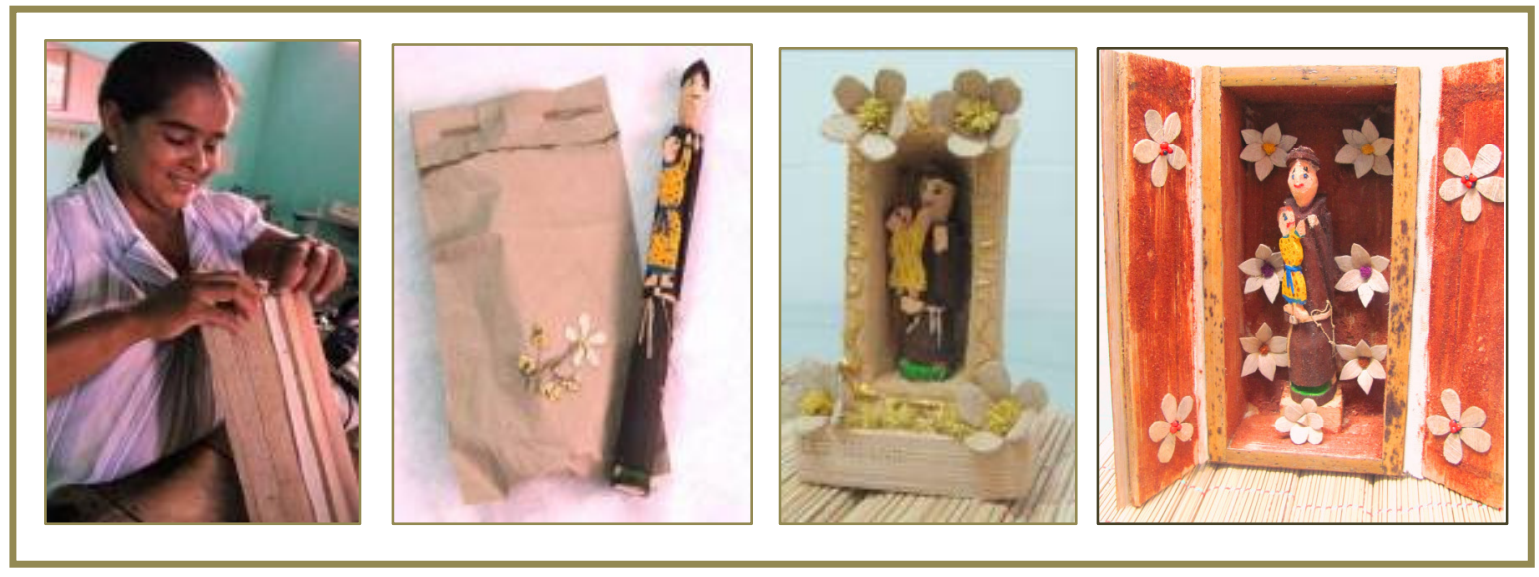

Figura 8: Imagens com a Artesã Rosicley e a produção de oratórios e embalagens da Associação de Bordadeiras e Artesãos de Serra das Araras. Fonte: Mourão (2011).

Figure 8: Images with Artisan Rosicley and producing oratorios and packaging of Embroiderers and Craftsmen Association of Serra das Araras. Source: Mourão (2011).

Os produtos artesanais com materiais locais desta comunidade é uma das heranças culturais na região. Em função das dificuldades em adquirir colas e resinas para acabamento dos produtos, os artesãos utilizam as técnicas de produção caseira. Aplicam receitas desenvolvidas pelos avôs, valorizando os recursos e tradições. Quanto ao ecoturismo, a comunidade desenvolve roteiros esquemáticos, que mostram onde se encontram as espécies vegetais e como preserva-las.

$\mathrm{Na}$ comunidade de Buraquinhos, a produção de esteiras de buriti é um ritual de gerações e gerações. Ninguém sabe ao certo quem começou a fazer as esteiras de buriti, mas assim se faz a cultura local. As Oficinas do Design incentivaram aos artesãos e produtores rurais a desenvolverem novos modelos de esteiras e experimentarem coloração da fibra do buriti.

Com a supervisão do IEF na região, surgem possibilidades de roteiros para o ecoturismo, pois existem muitas nascentes em tordo da comunidade, que garantem a manutenção do ecossistema. Assim, as oficinas abordaram a importância deste fato, para que os recursos naturais sejam preservados pelos habitantes locais.

\section{Discussão e resultados}

As oficinas de design, cultura e identidade atingiram as metas, colaboraram com conceitos, métodos e técnicas que podem contribuir para produção artesanal sustentável, com características regionalizadas, usando a matéria prima de resíduos vegetais locais. As atividades executadas foram experimentais, mas os produtos apresentados possuem potenciais para a expansão do artesanato na região. A melhoria da qualidade nos métodos de produção e o aproveitamento dos resíduos, gerando produtos diferentes, apontam que a identidade das comunidades está preservada em cada objeto.

Os produtos foram desenvolvidos integralmente pelos artesãos, sem a interferência da pesquisadora designer. Estes apresentam vínculo ao 
contexto cultural, aproveitando o despertar da comunidade quanto à utilização dos resíduos vegetais.

O respeito à diversidade possibilita a expansão de produtos diferenciados, inovadores e criativos. Cada comunidade não se interessa em copiar o trabalho da comunidade vizinha, mas observa a técnica e aprimora, criando novos produtos artesanais. Recorda-se ainda que a pluralidade de etnias em processo harmonioso na formação da sociedade brasileira, favoreceu a maturação da sua própria multiculturalidade (MORAES, 2008). O caminho do design brasileiro desponta na diversidade e não na unidade.

A força e a riqueza da constante renovação e criatividade podem contribuir para a estruturação da economia local. Assim, nascem outras formas de identificar o design, mais público associado aos valores culturais, de identidade e de domínio popular. Incidem sobre sob a expansão do design para outros aspectos, buscando qualificá-lo como processo criativo, inovador e provedor de soluções. Desta forma, incorpora-se o acréscimo do design na produção artesanal.

As organizações locais, os produtores rurais e os artesãos, estão atentos às contribuições para desenvolvimento do ecoturismo, através das possibilidades de produção artesanal para o crescimento da economia criativa, com vínculo nas áreas de preservação ambiental.

O desenvolvimento do ecoturismo é uma das metas do município. A natureza é um dos principais atrativos na região e a infraestrutura o principal problema. A sensibilização da comunidade quanto à utilização dos resíduos vegetais foi uma das metas deste trabalho, principalmente do uso dos buritis, pois esta é uma palmeira em abundância na região.

O resultado deste trabalho possibilitou uma nova visão em relação aos produtos artesanais, à medida que os artesãos perceberam a identidade do território. Verificou-se que as riquezas oriundas da biodiversidade e da cultura podem ser a base para o desenvolvimento de produtos e atrativos para o turismo de base local. É correto afirmar que o turismo de base local pode ser incentivado pelo design social. Inclusive, incentivam a economia local e contribuem para estimular o desenvolvimento sustentável do entorno de áreas protegidas.

\section{Considerações finais}

Para que a sustentabilidade se estabeleça, todos os fatores são importantes. Averiguar como os materiais são extraídos e o processo até o descarte envolve os sistemas amplamente. O processo de produção artesanal sustentável e o desenvolvimento de valores que promovam o ecoturismo devem ser contínuos, necessitando de acompanhamento e monitoria. Relatórios conclusivos foram apresentados à prefeitura de Chapada Gaúcha e parceiros locais na expectativa que possam desenvolver outras propostas.

É necessária aprendizagem social, mudança de comportamentos e compartilhamento com novos estilos de vida. Repensar e inovar, o que não significa necessariamente novas tecnologias. Inovar é ver sob outros 
ângulos, perspectivas diferentes. Assim, a cultura também é uma grande "teia de significados", tecida pelos próprios homens. Não é uma realidade posta, mas está sempre em construção, dependendo de muitas escolhas individuais nas percepções das sociedades. Nas atividades de oficinas para comunidades tradicionais, deve-se ter cuidado para não interferir na identidade local. Os símbolos construídos e aplicados pela sociedade, sendo pelas memórias estes podem fornecer o extrato da cultura local.

O que é sustentado numa comunidade sustentável não é apenas o crescimento econômico ou o desenvolvimento, mas toda a teia da vida da qual depende, em longo prazo, a nossa própria sobrevivência. Assim, o design e o ecoturismo são alguns recursos para o desenvolvimento em áreas de preservação. O resultado deste trabalho possibilitou uma nova possibilidade de produção artesanal, à medida que os artesãos perceberam a identidade em seu território.

As riquezas oriundas da biodiversidade e da cultura podem ser a base para o desenvolvimento de produtos e atrativos para o ecoturismo. Porém, são necessários investimentos para educação e desenvolvimento sustentável em regiões tão ricas em biodiversidade. E necessário buscar caminhos entre 0 ecoturismo e o design, que auxiliem a economia local, apresentando valores sociais, culturais e ambientais, que valorizem a relação do ser humano com a natureza.

\section{Referências bibliográficas}

BRITO, T.R.S. A sustentabilidade no turismo: a perspectiva da sustentabilidade no planejamento turístico dos municípios Faro (Portugal) e Belo Horizonte (Brasil). (Monografia). Curso de Curso de Graduação em Turismo da Universidade do Estado de Minas Gerais, 2012.

BONFIM, G.A. Design e informação. São Paulo: Design \& interiores, v.9, n.49, nov. 1998.

CAPRA, F. As conexões ocultas. São Paulo: Editora Cultrix, 2002.

IBAMA. Reserva Extrativista. Populações tradicionais. 2003. Disponível em: hptt/www.ibama.gov.br/resex/pop.htm. Acesso em: 10 jul. 2010.

IBAMA/FUNATURA. Plano de manejo do Parque Nacional Grande Sertão Veredas. Brasília, julho de 2003.

IBGE - Instituto Brasileiro de Geografia e Estatística. Disponível em: $<$ http://www.ibge.gov.br/home/presidencia/noticias/noticia visualiza.php?id noti cia=1766\&id pagina=1 > Acesso em:10 set. 2014.

IBGE. Cidades@. Disponível em: <http://www.ibge.gov.br/cidadesat/topwindow.htm?1>. Acesso em: 20 jun. 2014.

IBGE. IBGE lança o mapa de biomas do Brasil e o mapa de vegetação do Brasil, em comemoração ao dia mundial da Biodiversidade. 2007. Disponível

em: $<$ http://www.ibge.gov.br/home/presidencia/noticias/noticia visualiza.php?id noti cia=169>. Acesso em: 20 mai. 2014. 
IBGE. Produção da extração vegetal e da Silvicultura, Diretoria de Pesquisas, Coordenação de Agropecuária. Disponível em: <http://www.sidra.ibge.gov.br/>. Acesso em: 10 fev. 2010.

IUCN - International Union for Conservation of Nature and Natural Resources, United Nations Environment Programme, World Wildlife Fund, Food and Agriculture Organization of the United Nations, and Unesco. World Conservation Strategy: Living Resource Conservation for Sustainable Development. Gland, Switzerland: IUCN, 1980.

KELSEN, S. Diversidade cultural no sertão mineiro. Belo Horizonte: Overmundo.com.br. Postado em: 02 out 2007. Disponível em: $<$ http://www.overmundo.com.br/banco/diversidade-cultural-no-sertao-mineiro $>$. Acesso em: 23 abr 2014.

KINKER, S. Ecoturismo e Conservação da Natureza em Parques Nacionais. Campinas: Papirus, 2002.

LOURES, R.C.R. Sustentabilidade XXI: educar e inovar sobre uma nova consciência. São Paulo: Editora Gente, 2009.

MANZINI, E. Design para a inovação social e sustentabilidade: Comunidades Criativas, organizações colaborativas e novas redes projetuais. Cadernos do Grupo Altos Estudos. Rio de Janeiro: E-papers, 2008.

MEDEIROS, J. et. al. .Aproximação do design e artesanato para um desenvolvimento sustentável, na comunidade de Guaraqueçaba-PR. Curitiba: CADMA, 2006. Disponível em: $<$ http://www.pessoal.utfpr.edu.br/macloviasilva/arquivos/aprox design artesan guaraq.pdf $>$. Acesso em: 23 abr 2014.

MENDES, X. História do vale do Rio Urucuia em Minas Gerais. Academia Planaltinense de Letras. Postado em 25 Fev 2011. Disponível em: $<$ http://academiaplanaltinensedeletras.blogspot.com/2011/02/historia-do-valedo-rio-urucuia-em.html>. Acesso em: 20 jun. 2014.

MTUr - MINISTÉRIO DO TURISMO. Ecoturismo: orientações básicas. Brasília: Ministério do Turismo, 2010.

MORAES, D. Design e multiculturalismo.(Org.) Dijon de Moraes, Belo Horizonte: Centro de Estudos Teoria, Cultura e Pesquisa em Design. UEMG, 2008.

MOURÃO, N.M. Sustentabilidade na produção artesanal com resíduos vegetais: uma aplicação prática de design sistêmico no Cerrado Mineiro. 2011. 206f. Dissertação (Mestrado em Design) - PPGD/Universidade do Estado de Minas Gerais, Belo Horizonte, 2011.

PORTALCHAPADAGAÚCHA. www.chapadagaucha.com. Disponível em:, $<$ http://www.chapadagaucha.com/index.php?option=com morfeoshow\&task=vie w\&gallery=10\&ltemid=69 >. Acesso em: 10 out. 2014.

PROJETO GRIO - CULTURA EM CHAPADA GAUCHA. Disponível em: $<$ http://www.acaogrio.org.br/index.php?pg=projeto\&idreal=000076\&idpj=054>.

Acesso em: 23 abr 2014.

ROSA, J.G. Grande Sertão: Veredas. 19. ed. Rio de Janeiro: Nova Fronteira, 2001. 
SALGADO, C.L. A prática educativa e o desenvolvimento territorial: um estudo de caso no município de Chapada Gaúcha, MG. Dissertação de mestrado Unb: Brasília. DF. 2010.

SILVA, C.E.M. O Cerrado em disputa: Apropriação global e resistências locais. Brasília: Confea, 2010.

VEIGA, J.E. Insustentável utopia do desenvolvimento. In: LAVINAS, L.; CARLEIAL, L.M.F.; NABUCO, M.R. (orgs) Reestruturação do espaço urbano e regional no Brasil. São Paulo: ANPUR-HUCITEC, 1993.

YIN, R. K. Estudo de caso: planejamento e métodos. 3 $3^{a}$ ed. Porto Alegre: Bookman, 2005.

\section{Notas:}

1 World Conservation Strategy, Gland,Switzerland: International Union for the Conservation of Nature.

2 Segundo Censo/2010, do IBGE - Instituto Brasileiro de Geografia e Estatística.

${ }^{3}$ O tempo de uma oficina depende da relação entre o conteúdo e público alvo. Fatores como número de participantes, material e recursos também alteram o tempo de duração. Uma oficina arte educação para auxiliar no desenvolvimento das técnicas artesanais para adultos analfabetos na área rural, por exemplo, necessita de 3 ou 4 encontros de 4 horas seguidas. A mesma oficina para adulto alfabetizados, no perímetro urbano, necessita de apenas uma tarde.

Nadja Maria Mourão: Universidade do Estado de Minas Gerais, Belo Horizonte, MG, Brasil.

E-mail: nadjamourao@gmail.com

Link para o currículo Lattes: http://lattes.cnpq.br/5407300132397950

Rita de Castro Engler: Universidade do Estado de Minas Gerais, Belo Horizonte, MG, Brasil.

E-mail: rcengler@uol.com.br

Link para o currículo Lattes: http://lattes.cnpq.br/1848076566428564

Lidja Mourão Lataro Hohene: FM\&F Tecnologia, Belo Horizonte, MG, Brasil.

E-mail: lidja_m@yahoo.com.br

Link para o currículo Lattes: http://lattes.cnpq.br/7215280515882806

Data de submissão: 15 de abril de 2013

Data de recebimento de correções: 08 de outubro de 2014

Data do aceite: 08 de outubro de 2014

Avaliado anonimamente 